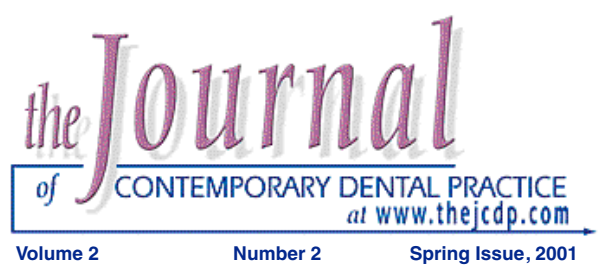

\title{
Herbal Nutriceuticals: A Primer for Dentists and Dental Hygenists
}

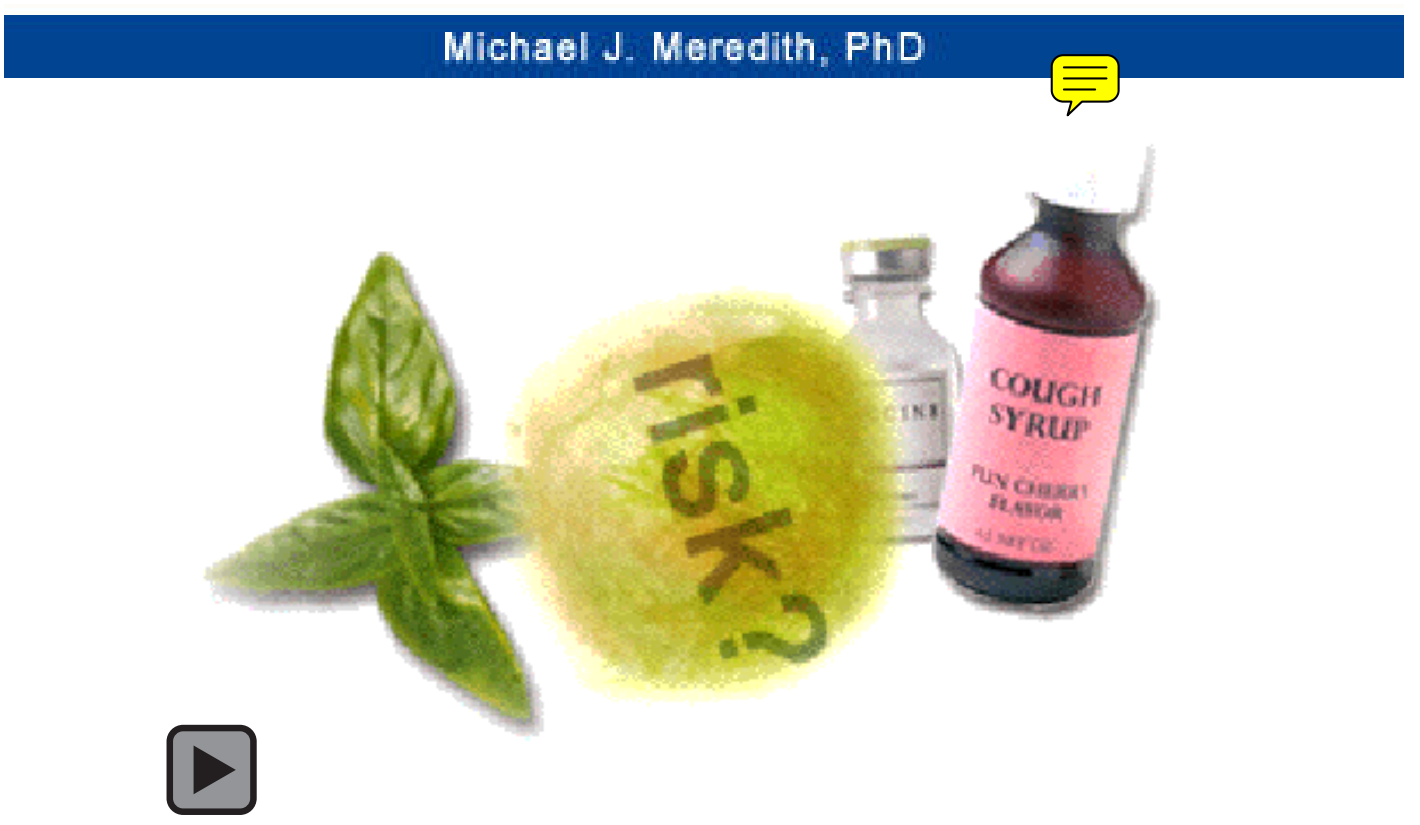

\section{Abstract}

Herbs have been in use for centuries to prevent and control disease. In recent history demand by the public for herbal supplements has created a multimillion-dollar industry. Herbal extracts are effective because they interact with specific chemical receptors within the body and are in a pharmacodynamic sense, drugs themselves.

A matter for public concern is that herbal supplements are currently independent of regulation by the Federal Drug Administration (FDA). The FDA considers herbal products to be dietary supplements, not drugs. The National Toxicology Program has recently started to examine the composition and standardization of commercial preparations to identify potential health hazards from contaminants or product over use. Many herbal preparations have significant pharmacological effects. The problem that arises for the dental professional is the effect these products have in concert with prescription medications as well as effects on the patient's general response to medication and dental treatment. Drug interactions with the large number of commercially available herbal products can be grouped by the mechanism of most common interactions. These major types of reactions are: (1) alteration of drug metabolizing enzyme activity, (2) interactions with the blood clotting process, and (3) alteration of the inflammatory and immune response.

The widespread use of herbal supplements makes it essential that healthcare providers become informed about this aspect of a patient's personal health practices.

Keywords: Nutriceuticals, herbal supplements, monoamine oxidase inhibitor, St. John's wort, mixed function oxidases, kava-kava, goldenseal, ginseng, garlic, evening primose oil, echinacea, ginger, ginko biloba, sanguinarine 


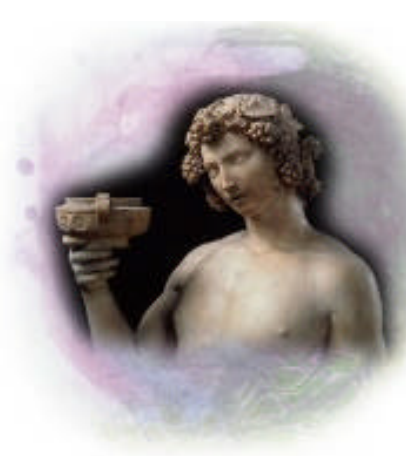

Introduction

Nutriceuticals is a term coined by the popular press as a new way of looking at health maintenance for many people. In ancient times, plants were assigned curative powers based on shape or color; the concept that later became know as the doctrine of signa tures in the Helenistic medical tradition.

Phytotherapy, or phytomedicine, has been a part of both eastern and western medical traditions since the King of Sumaria ordered a summary of current knowledge (about 250 medicinal plants) to be assembled in approximately 2000 BC. over 2000 plants were thought to have medicinal properties in the ancient world. The Chinese began using ginseng at least 3000 years ago, and Native Americans were using willow bark tea to reduce fever about the time most of the "civi lized world" was under Roman rule. Every civi lization that has recorded its progress produced a body of knowledge addressing the use of medici nal plants (pharmacognacy). Though displaced to some degree by the rise of "modern medicine," herbalists and herbal preparations have contin ued to be part of folk and Oriental medical prac tice. The recent rise in popularity of these materi als in American and European societies may reflect a growing discontent with established medical practice, or perhaps an interest in more "nat ural " modes of healthcare. This is especially true among the elderly. (Table 1)

Table 1. The Top Ten Herbal Remedies

\begin{tabular}{|c|c|c|c|}
\hline Common Name & Desired Effect & $\begin{array}{c}\text { Known Pharmacological } \\
\text { Effect }\end{array}$ & $\begin{array}{l}\text { Drugs Potentially } \\
\text { Affected }\end{array}$ \\
\hline Ginko & $\begin{array}{l}\text { Memory and circulation } \\
\text { improvement }\end{array}$ & $\begin{array}{l}\text { Antioxidant, platelet } \\
\text { aggregation inhibitor }\end{array}$ & Anti-coagulants \\
\hline Ginseng & $\begin{array}{l}\text { Improved immune function, } \\
\text { stress reduction }\end{array}$ & $\begin{array}{l}\text { Platelet aggregation } \\
\text { inhibitor, immune stimulator }\end{array}$ & Anti-coagulants \\
\hline Garlic & $\begin{array}{l}\text { Cholesterol reduction, } \\
\text { cardiovascular health }\end{array}$ & $\begin{array}{l}\text { Platelet aggregation } \\
\text { inhibitor }\end{array}$ & Anti-coagulants \\
\hline Echinacea & Improved immune function & $\begin{array}{l}\text { NK cell increase, IgG/lgM } \\
\text { production increase }\end{array}$ & $\begin{array}{l}\text { Cyclosporine, ketoconazole, } \\
\text { methyltrexate }\end{array}$ \\
\hline Goldenseal & Improved immune function & $\mathrm{lgG} / \mathrm{lgM}$ production increase & Erythromycin antibiotics \\
\hline St. John' s Wort & $\begin{array}{l}\text { Anti-anxiety/anti- } \\
\text { depressant }\end{array}$ & $\begin{array}{l}\text { Induce P-450, inhibit MFO, } \\
\text { inhibit seratonin uptake }\end{array}$ & $\begin{array}{l}\text { Paroxatine, Sertraline, } \\
\text { Nefazadone, Digoxin, } \\
\text { Theophiline, Indinavir, } \\
\text { Cyclosporin, Oral } \\
\text { contraceptives }\end{array}$ \\
\hline Saw Palmeto & $\begin{array}{l}\text { Prostate health, urinary } \\
\text { anticeptic }\end{array}$ & Diuretic, antiandrogenic & $\begin{array}{l}\text { Estrogen replacement, oral } \\
\text { contraceptives }\end{array}$ \\
\hline Grape seed extract & Antioxidant & & \\
\hline Evening Primrose & $\begin{array}{l}\text { Antioxidant, omega fatty } \\
\text { acids }\end{array}$ & Anti-inflammatory & \\
\hline Cranberry & Urinary tract health & & \\
\hline
\end{tabular}




\section{Introduction}

Herbal remedies are big business, with the top ten selling botanicals accounting for $\$ 600$ million to $\$ 2$ billion in the Unites States in $1998 .{ }^{2}$ In 1994 Europeans spent $\$ 6$ billion, while the Japanese spent $\$ 2.1$ billion dollars on herbal preparations. ${ }^{3}$ A matter for public concern is that herbal supplements are currently independent of regulation by the Federal Drug Administration (FDA). The FDA considers herbal products to be dietary supple-

ments, not drugs. This means herbal products do notneed to meet the "safe and efficacious" stan dards applied to materials classified as"drugs." However, the National Toxicology Program has recently started to examine the composition and standardization of commercial preparations to identifypotential health hazards from contaminants or product over use. ${ }^{4}$

The term nutriceutical refers to doses of vitamins, minerals, nutrients, and micronutrients in excess of the body's needs (2 to 10 times the recom mended daily allowance). ${ }^{5}$ Consumption of these plant extracts for the purpose of improving or pre venting some health related conditions places them in the nutriceutical category, despite the fact the mechanism of action is more often pharmacological in nature than nutritional. Identification of medicinal herbs as natural may be at the center of the increasing concern about these preparations. These plant-derived preparations are often inadvertently omitted from medical histories; there seems to be a lack of understanding of the potent pharmacological actions of many of these extracts. Patients sometimes assume that because these "drugs" were recently green and growing they aren't in the same cate gory as the pills and capsules they more com monly associate with the term "drug." ${ }^{6}$
With the possible exception of meprobromate, the first drug designed from structure/activity relation ships, the first examples of most classes of drugs are natural products. Examples of these include: opiates, the salicylates, scopolamine, and the car diac glycosides like digoxin. Approximately one quarter of all prescription drugs have some compo nent derived from plants. This includes about 100 of the most commonly prescribed drugs. ${ }^{7}$

Herbal extracts are effective because they interact with specific chemical receptors within the body and are in a pharmacodynamic sense, drugs them selves. Current estimates suggest that $18 \%$ of Americans take prescription medications in conjunction with herbal remedies. ${ }^{8}$ This translates into 15 million people in the United States alone. The potential for interaction between prescription medications and herbal extracts is significant. 9, 10

This paper will review the pharmacology of the most common herbal nutriceuticals and address the spe cific mode of interaction with different classes of prescription drugs. No attempt will be made to cover all herbal remedies or all prescription drugs of interest to dental professionals. Only some of the most commonly used herbs and herbal preparations in oral conditions such as inflammation, blood clot ting, and alteration of drug metabolism will be cov ered in this paper.

\section{Herbal Remedies: Overlapping Pharmacology \\ Many herbal preparations have signif- icant pharmacological effects. The problem that arises for the dental pro - fessional is the effect these products have in concert with prescription med - ications as well as effects on the patient's general response to medica- tion and dental treatment. Drug inter - actions with the large number of com- mercially available herbal products can be grouped by the mechanism of most common interactions. These fall into three major types of reactions:}

-Alteration of drug metabolizing enzyme activity

- Interactions with the blood clotting process

-Alteration of the inflammatory and immune response 


\section{Pharmacology Flashback-}

Monoamine Oxidase (MAO):

An enzyme that catalyzes the conversion of primary and secondary amines to alkenes and

aldehydes. Most commonly associated with the metabolism of epinephrine, norepinephrine

serotonin, dopamine, and other neuroactive amines. Inhibitors of monoamine oxidase

(originally hydrazine and hydrazine derivatives) were first introduced in the 50's to treat

depression but caused hypotension, leading to their first pharmacological use, the treatment

of hypertension. MAO inhibitors were not found to be safe in the hypertensive patient or patients

with cardiovascular disease and are now contraindicated by these conditions. Newer MAO inhibitors

are currently used to treat depression and as an adjunct to levadopa therapy for Parkinson's

disease. These inhibitors are being reexamined for theability to specifically inhibit the $A$ and $B$

isozymes of MAO, looking for more selective MAO inhibitors, free of the hypotensive/hypertensive

side effects.

\section{Alteration of Drug Metabolizing Enzyme Activity}

\section{St John's Wort}

St John's wort (Hypericum perforatum) is among the most commonly used and well studied herbal remedies. ${ }^{11}$ St. John's wort has been in folk wis dom since the time of the ancient Greeks as an agent to promote a feeling of well being, combat insomnia, and depression. However, there is disagreement about the efficacy of St. John's wort in the treatment of depression. ${ }^{1,12,13}$

The active ingredients in St. John's wort are a family of polycyclic compounds, the hypericins, which have a wide variety of physiological proper ties. Among the most dramatic of these proper ties is increased photosensitivity. ${ }^{14}$ Hypericin andpseudohypericin in or on the skin are photoacti vated to produce free radicals that initiate an immediate hypersensitivity-like reaction producing erythema and weal. Although this may seem like more of a problem for the gardener than the phar macologist, photoactivation of hypereicin is at the heart of the compound's antiviral and anticancer effects and is currently receiving significant research. ${ }^{15-19}$

St. John's wort is also known to increase sensitiv ity to ionizing radiation. ${ }^{20}$ It's not known if this represents a risk factor for dental radiography, but hypericin may be a risk factor in higher dose ion izing radiation exposure such as cancer radiother apy. The mechanism by which St. John's wort exerts a beneficial effect on depression is not fully understood. The hypericins are known to be of the chemically active species. When tested, receptor binding was not very strong to likely receptors including adenosine and steroid recep- tors. The exceptions are the gamma amino ben zoic acid (GABA) A and B receptors. ${ }^{11}$ GABA is the major inhibitory neurotransmitter in the mammalian central nervous system. Antagonism of the GABA receptors could interfere with the binding of other drugs such as the benzodiazip ines and barbiturates as well as produce a direct inhibitory effect on neurotransmissions.

Hypericin and pseudohypericin inhibit MAO activi ty, but they are not potent MAO antagonist. ${ }^{21,22}$ The pharmacological effect of St. John's wort is thought to be initiated by a combination of mild inhibition of MAO, catechol-O-methyl transferase (surpressing dopamine turnover), and inhibition of serotonin reuptake. ${ }^{22,23}$ Through these concerted mechanisms, St. John's wort may affect mood by increasing norepinephrine activity and slowing serotonin clearance.

The most significant potential for prescription drug interactions with St. John's wort, acting as an inhibitor of MAO, is with the serotonin-uptake inhibitors. Inconsistencies in the preparation of St John's wort have led to variable responses and unpredictable effects on mood elevation. Paroxetine ${ }^{24}$ trazodine, sertraline,$^{25}$ and nefazadone have all been linked to St. John's wort-induced serotonin syndrome (sweating, hyperreflexia, and shivering) and tremors in mild cases; seizure and coma in severe cases. ${ }^{26,27} \mathrm{An}$ additional effect of St. John's wort and hypericin caused by MAO inhibition is the alteration of his tamine levels. MAO is responsible for production of the major clearance metabolite of histamine. Moreover, MAO inhibitors also block histamine Nmethyltransferase, further decreasing histamine turnover. ${ }^{28}$ Decreasing the clearance rate of histamine could affect the enhancing histamine- 
dependent processes producing physiological responses ranging from the well known allergic rhinitis to increased $\mathrm{HClsecretion}$ by the parietal cells of the stomach, as noted for the MAO inhibitors selegiline. ${ }^{29}$ There is a strong possibility that St.John's wort acts to counter the effect of antihistamines increasing the histamine levels competing for receptor binding site occupancy. MAO

inhibitors vary in the degree of anticholinergic effect observed (xerostomia, decreased gastric motility, etc.). Tranylcypromine is known to have pronounced anticholinergic properties, while selegiline and phenylzine are not noted for these effects. Variability is probably due to the number of biological amines antagonized by the drug. It is not know whether hypericin's antagonism is limited to seretonin or extends to dopamine and norepinephrine.

\section{Kava-Kava}

St. John's wort is not the only herbal preparation to alter MAO activity. Kava-Kava (Piper methysticum) is a popular herb from the South Pacific with significant MAO inhibitory activity. ${ }^{23-31}$ The kavapyrones have been shown to have great potential for reducing anxiety and stress without the side effects associated with the tricyclic anti depressants. ${ }^{32}$ Levels of serotonin are significantly increased which accounts for the sleep inducing properties. ${ }^{33}$ It has been shown to be a safe and effective tranquilizer and antidepressant ${ }^{34}$ perhaps resulting from the ability to inhibit norepinephrine and epinephrine uptake at neuronal surfaces. ${ }^{35}$ The potential drug interactions resulting from kava-kava would be similar to those observed with St. John's wort; decreased serotonin uptake and decreased dopamine oxidation. However, an important addition for the dental practitioner should be made. As with cocaine, the inhibition of epinephrine uptake by kava-kava could have profound cardiac consequences for patients receiving local anesthetics containing epine $\mathrm{p} h \mathrm{r}$ i $\mathrm{n}$ e .

\section{Compounds in Foods}

There are many other possible interactions of MFO inhibitors outside besides those associated with prescription drugs. Foods containing tyramine (aged cheese; yeast extract; soy sauce; fava bean or broad beans; smoked meats; pick led meats; poultry and fish (lox, smoked salmon); pickled fish; bananas and avocados just to name a few) should be avoided as well as foods and beverages containing caffeine and theobromine (such as tea and coffee). Caffeine can produce a severe hypertensive crises or dangerous cardiac arrhythmias in patients taking an MAO inhibitor.

\section{Monoamine Oxidase (MAO) Inhibitors and Dental Treatment}

In dental practice, perhaps the most significant possibility for acute drug interaction between MAO inhibitors, such as St. John's wort, is with epinephrine. Drugs that block MAOs lead to the accumulation of serotinin and norepinephrine within the central nervous system. Epinephrine can increase the effect of norepinephrine result ing in unexpected transient hypertension. This risk is most severe in the elderly patient or the patient with a history of heart disease. The potential for unexpected elevation and blood pressure when using epinephrine in local anes thesia suggests the cautious use of this vasocon strictor in patients taking MAO inhibitors, including St John's wort.

\section{Mixed Function Oxidase (MFO) Alteration}

\section{St. John's Wort}

St. John's wort leads the list of herbs that have been suggested to alter Cytochrome P-450 MFO activity, however, there is disagreement about the direction of the effect, induction, ${ }^{36}$ or inhibition. ${ }^{37}$ The balance of data suggests that St. John's wort leads to an increase in Cytochrome P-450 MFO induction, producing selective increases in biotransformation andfaster clearance of drugs metabolized by the increased P450 species. 


\section{Pharmacology Flashback:}

The cytochrome P-450 mixed function oxidases (MFO's) are a large family of heme containing microsomal enzymes that begin the process of biotransformation by adding polar substituents such as hydroxyl groups or by dealkylating, i.e., demethylation. These modifications of drugs and other compounds lead to less reactive, more water-soluble molecules. In most cases, Cytochrome P-450 dependent metabolism is the first step in drug clearance. However, some drugs are activated by P-450 dependent metabolism. The cytochrome P-450 MFOs are coded for by many separate genes, arranged into gene families. Each enzyme is regulated independently in response to changing metabolic needs. The presence of a substrate for a particular P-450 MFO can cause induction, an increase in its synthesis, increasing the rate of clearance for that molecule. An inhibitor of P-450 activity can lead to the accumulation of drugs that metabolize via that cytochrome P-450 isozyme. Substrate specificities are very broad and substrates for one cytochrome P-450 are often inhibitors or inducers of another. This is the basis of acquired drug cross-tolerance.

St. John's wort contains at least 10 families of compounds that are known to induce P-450 activ ity. ${ }^{38}$ Among these are the xanthones, flavinoids, bioflavinoids; all demonstrated inducers of the P450 isozyme CYP3A. Recently, St. John's wort was found to be the cause of an acute heart transplant rejection. Use of St. John's wort by the recipient caused an increase in the $\mathrm{P}-450$ isozyme that oxidizes cyclosporin, producing a drop in cyclosporin level and rejection of the transplanted heart. ${ }^{39}$

A similar situation was found for another CYP3A substrate, indinavir, an HIV protease inhibitor. St. John's wort was found to induce P-450 MFOs leading to a reduction by $50 \%$ in the plasma lev els of indinavir. ${ }^{40}$ Since members of the cytochrome P-450 CYP3A MFO family are involved in the metabolism of other HIV protease inhibitors and non-nucleotide reverse transcriptase inhibitors, St. John's wort should be avoided during these antiviral treatments. The anti-herpetic, Acyclovir, often prescribed by dentists, would not fall under this warning. Other sub strates of this MFO include diazepam, caffeine, theophylline, digoxin, and, very significantly, most oral contraceptives. ${ }^{41}$

Inhibition of this cytochrome P-450 isozyme has additional significance in dentistry because the erythromycin antibiotics (including clarithromycin; no data is available on azithromycin) are sub strates for CYP3A. ${ }^{42,43}$ The erythromycins (including clarithromycion and azithromycin) are generally thought of as inhibitors of drug metabolism. To be more specific, the $3 \mathrm{~A} 3$ isozyme of cytochrome P-450 MFO is responsible for the metabolism of carbamazipine, codeine, and a number of other drugs of dental importance. However, in this case, erythromycin can be thought of as being cleared more rapidly due to MFO induction. Increased P-450 activity could alter the clearance time for these important antibi otics

The full extent of the ability of St John's wort to induce the MFOs is not known. It is very proba ble that other specific isozymes of the cytochrome P-450 MFO are induced or inhibited by this botanical. The potential for interaction with prescription drugs is, therefore, very signifi cant and worse yet, unknown.

The opposite is true of Goldenseal, a herb which is a potent inhibitor of CYP3A. ${ }^{44}$ Therefore, goldenseal, which is used to treat a wide variety of skin related problems as well as constipation, menstrual pain, and digestive disorders could potentially cause an increase in the serum levels of the erythromycins and other substrates of these cytochrome P-450 MFOs.

Interactions with the Blood Clotting Process It's common knowledge among hay producers that red clover hay improperly dried produces several compounds that inhibit blood clotting. The best known of these is the coumadin group, including dicumarol. Numerous congeners of dicumerol have been made, and fortunes have been made along with them. One of them, Warfarin (Wisconsin Alumni Research Foundation-arin), is perhaps the world's most common rodentacide. 
Many plant products can act to inhibit coagula tion. Almost all act as Vitamin $\mathrm{K}$ analogs, block ing the fibrin-clotting cascade. These include three of the most popular herbal supplements: ginko biloba, garlic, and ginseng. Ginger has also been found to have an effect on blood clotting. Ginko, garlic, ginger, and ginseng have all been found to slow clotting. The mechanisms by which they work differ significantly.

\section{Garlic}

Besides improving the flavor of food, garlic is taken in large doses to reduce serum cholesterol and blood pressure. This is one of the more thor oughly studied medicinal plants and is reviewed with regard to cardiovascular health elsewhere. ${ }^{45}$ In perhaps the best controlled experiments, garlic was found to reduce serum cholesterol by 0.65 $\mathrm{mmol} / \mathrm{l}$, or about $25 \mathrm{mg} / \mathrm{dl}$ (from a study group mean of $268 \mathrm{mg} / \mathrm{dl}$ ). ${ }^{46}$ Recent studies have shown little or no effect on any aspect of choles terolmetabolism. ${ }^{47}$ Studies of garlic's effect on blood pressure show a slight reduction in about half the subjects, although the effect was not con sistently on the systolic or diastolic pressure. ${ }^{48}$ Studies of garlic pharmacology are notoriously hard to do properly because it is impossible to blind the subjects due to the smell. Since the effects of garlic are associated with the low molecular weight sulfide components of the herb (allylic sulfides), placebos altered to mimic the odor possess some unintended pharmacological effect by inadvertently supplying active pharmacological materials. Garlic oil is known to inhibit platelet aggregation. ${ }^{49,50}$ While there is no evidence garlic can effect clotting time in a healthy patient, several reports of garlic potentiation of warfarin and other anticoagulants can be found.

\section{Ginger}

Ginger has been found to be useful in the treat ment of motion sickness and vertigo. ${ }^{51,52}$ Single doses of ground ginger rootperformed better than standard prescription drugs in preventing nausea and vomiting in several trials. However, ginger is apotent inhibitor of thromboxane synthetase, ${ }^{53,54}$ thereby, inhibiting blood clotting. Again, potentiation of anticoagulants is a risk. As with garlic, effects in a healthy patient are unknown but it seems very likely that ginger could induce exces sive bleeding during dental procedures if con sumed in high levels. It's interesting to note that consumption of food items (for example, the Chinese hot and sour soup or the pickled ginger served with sushi) could easily provide the one gm dose of ginger root found to be pharmacologi cally active in clinical trials.

\section{Ginko biloba}

Ginko biloba is the most popular herb in Europe and has recently been approved in Germany to treat dementia. ${ }^{56}$ Ginko extracts contain a large number of flavinoid and terpenoid compounds that are thought to provide the extract's antioxi dant capacity. Among these, ginkolide B, a glyco sylated flavinoid, is known to be a potent inhibitor of platelet aggregation. ${ }^{57}$ Cases of spontaneous hematomas have been reported as well as hyphemia. ${ }^{58}$ Use of ginko extract must be closely monitored in patients on anticoagulant therapy, or those who suffer bleeding disorders of any sort regardless of whether the disorder is nutritionallyinduced or from such conditions as extended NSAID use.

\section{Ginseng}

Ginseng has been recommended for everything from mood enhancement to hypertension and may well have an effect on all of them. Ginseng extracts contain a very wide variety of known pharmacologically active compounds. However, standardization and outright fraud has been a problem. Analysis of saponin and panoxide showed that only about $25 \%$ of early commercial "ginseng" extracts contained any ginseng at all. ${ }^{59}$ Consumer Reports found striking differences in the ginsenoside contents of 10 brands tested. ${ }^{60}$ Additional confusion arises due to different sources of what is called ginseng: Siberian gin seng, American ginseng, Oriental ginseng, different species within the genus Panax. Along with ginger and garlic, ginseng (in a standardized product) has been found to be useful in reducing blood glucose in type II diabetics. ${ }^{61}$ The mechanism of action is unknown, making ginseng/drug interactions less clear. Ginseng has a central nervous system stimulant activity and may be working through an unidentified steroid receptor. Other ginseng effects are better understood. Many of the polycyclic aromatic components of ginseng, found in all ginseng varieties tested, are 


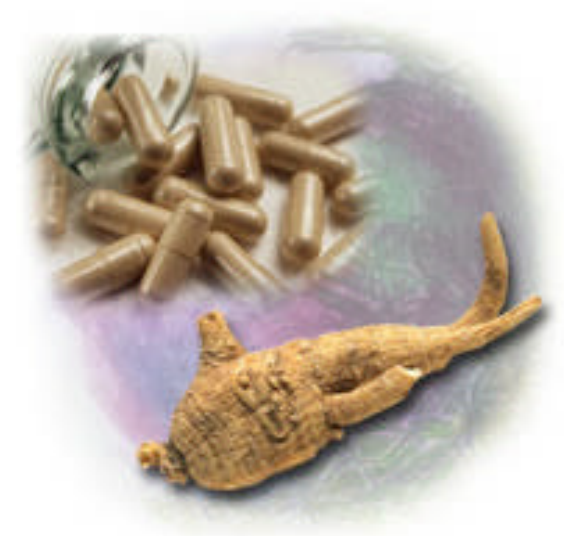

known to antagonize platelet function. This accounts for the numerous reports of bleeding related events ranging from destabilization of dicumarol therapy ${ }^{62-64}$ to vaginal bleeding. ${ }^{65}$ Recent reports showing a limited interaction with ginseng and warfarin not withstanding, it is probably prudent to consider ginseng use detrimental to patients with bleeding problems or look to ginseng as a possible source of unexpected clotting delays. ${ }^{66}$

\section{Echinacea}

The best known and most widely used plant alter ing inflammation and immune response is the American Coneflower, Echinacea sp. These plants are part of the Native American pharmacopoeia in all areas of North America where Echinacea is indigenous. Wustenberg ${ }^{67}$ describes these preparations as "immunobalancing" and "phytoimmunomodulators," and Sun et al ${ }^{68}$ suggests a prophylactic role by nonspecific immune stimulation. Some effect on the immune system has been demonstrated. Rehman et $\mathrm{al}^{69}$ found an increase in IgG and IgM production after treat ment. An increase in natural killer cells (NK cells) and antibody dependent immunity was observed by See and coworkers. ${ }^{70}$ Some recent success in treating colds has been noted, ${ }^{71}$ but based on clinical studies, only a $10 \%$ risk reduction for upper respiratory infection could be attributed to Echinacea. $^{72}$ Others conclude it may be of some limited benefit. ${ }^{73}$ Hepatotoxicty has been observed with Echinacea and treatment should be limited to 8 weeks or less continuous exposure $^{74}$ and not used with other drugs producing liver effects such as methyltrexate, ketoconazole, ${ }^{63}$ and phenytoin. ${ }^{75}$ Since Echinacea may function as an immunostimulant, use with immunosuppresants like corticosteroids and cyclosporine is contraindicated. However, this does not preclude the use of prednisone for con trol of acute inflammation, i.e., after dental extrac tion, in patients taking Echinacea. An additional problem with Echinacea preparation has been standardization. The pharmacologically active glycosides are not highly soluble in alcohol so methods of extraction are crucial to the efficacy of the preparation. ${ }^{76}$ Water versus alcohol extraction yields a product with widely varying ingredients.

Use of Echinacea to relieve colds may be of lim ited value, but these plants may have a useful role in regulating the inflammatory response. Alkamides isolated from Echinacea roots have been shown to inhibit both cyclooxygenase and 5-lipoxygenase. ${ }^{77,78}$ By inhibiting the production of the prostaglandin-2 and leukotriene-4 series of inflammatory mediators, Echinacea may serve as an effective inhibitor of the inflammatory response.

\section{Sanguinarine}

Another plant product proposed to alter the inflammatory response is sanguinarine, derived from the bloodroot, Sanguinaria canadensis. Although a modest inhibitor of 5-lipoxygenase ${ }^{79}$ no inhibition of cyclooxygenase by sanguinarine was found, thereby, only suppressing one side of the proinflammatory lipid synthesis. Moreover, topical sanguinerine is unlikely to have sufficient time to exert an effect by this mechanism. Sanguinerine has been marketed in the past as a plant derived inhibitor of oral inflammatory response (gingivitis) as an ingredient of a common mouthwash.

\section{Goldenseal}

Goldenseal (Hydrastis canadensis) has also been found to be an immune modulator. Used as a tonic for fever and cough by native Americans of the East, goldenseal has a similar effect on IgG and IgM production in rats. ${ }^{69}$ Goldenseal's use may be limited by its ability to inhibit cytochrome P-450 as noted above. ${ }^{44}$

\section{Evening Primrose Oil}

An interesting and little known modulator of inflammation is evening primrose oil. An excellent source of the polyunsaturated fatty acid gamma-lenolenic acid (18:3n-6, known as GLA), evening primrose oil has been tested as a possible means of controlling inflammatory conditions such as arthritis ${ }^{80}$ 
and more significantly for dentistry, Sjögren syndrome. GLA levels are depressed in patients with Sjögren syndrome.81 GLA is elongated to form DGLA (20:3n-6), the precursor of prostaglandin $\mathrm{E} 1$, an anti-inflammatory prostaglandin as well as an inhibitor of the 5lipoxygenase and the production of the proinflammatory prostaglandin, leukatriene B4. The net result is a movement of the immune system away from inflammation. ${ }^{82}$

Early studies showed evening primrose oil, com bined with B-complex vitamin supplementation, had a positive effect on Sjögren syndrome after 8 weeks of treatment as measured by tear produc tion. ${ }^{81,83}$ However, larger studies have not been done to investigate these findings further. No fur ther information is available on the efficacy of evening primrose oil in treating Sjögren's syn drome. This is unfortunate since there are very few or some would say no effective treatments for Sjögren syndrome. Nutritional modulation of inflammatory response could be a useful strategy against Sjögren syndrome and other inflammatory related conditions.

\section{What Should Patients be Told About Herbs}

Any discussion the health professional has with a patient about herbal supplements should be conducted with caution. Patients are likely to feel an herbal supplement is of value to their health and well being, thus, making it difficult to give guid ance without interfering with the patient's ideas of self-determination. The dental aspects of herbal supplementation are not as diverse as those faced by the physician. However, plant extracts affecting inflammation and bleeding are of signifi cant interest to the dental professional.

If the conversation is initiated by observations made by the dentist or hygienist during treatment, direct inquires are certainly justified. This is especially true of circumstances leading to unusu - al bleeding. If the patient inquires about the effects of a particular herb, it is essential the facts about herbal supplements be presented as dis passionately as possible to allow the patient to make an informed decision. However, the dental professional is also obliged to supply professional judgment. Based on the current understanding of the interactions and mechanisms of action of these supplements as well as the patient's med ical history, a clear and reasoned recommendation can be made without producing patient resist ance or antagonism.

A more difficult question to answer is about the benefits of herbal supplements. Whatever the dental professional says, will either conflict or confirm the patient's preconceived notions. Therefore, factual knowledge is essential. In this scenario the practitioner can intervene to provide the patient with good information about herbal supplements and sufficient knowledge of available resources.

Patients need to understand that the FDA regulates herbal products as food supplements, not drugs. Therefore, they don't have to pass the safe and efficacious standards to which prescription medications are held. The labels are not obliged to point out risks, nor do they guarantee the herb products are marketed in a composition or form that can be absorbed. Also, these prod ucts may have other ingredients in addition to those on the label. ${ }^{7}$

\section{Guidelines for Patients Using Herbal Supplements}

A set of useful guidelines for patients using or interested in using herbal supplements would include the following:

-Disclose to the health provider all non-prescrip tion medications and vitamins, since herbal sup plements are known to interact with prescription drugs.

-Be sure to follow instructions for taking the herbal supplement. It may be inappropriate to take too much, or too little and the patient may be putting themselves at risk for potential side effects 


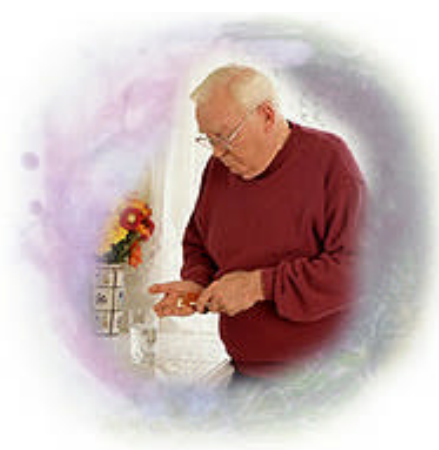

-Pregnant or breast-feeding women should avoid herbal supplements. Remember some herbal preparations are known to be teratogenic.

-Avoid mixtures of herbs to minimize unexpected effects and unlisted contaminants.

-Any unexpected reaction while taking herbal supplements should be reported to the health practitioner. These include abdominal cramping, abnormal bleeding, bruising, changes in pulse or heart rate, dizziness, visual aberrations, hives, rash, or other allergic symptoms.

- Herbal supplements should never interfere with standard medical care.

- Children and elderly patients should not use herbal supplements without appropriate medical consultation.

- For questions about herbs, seek advice from your healthcare provider or ask for a referral to someone with the proper knowledge of the sub ject. Keep in mind that the clerk in a health food store is there to sell products, not act as a health care information provider

\section{Information Resources}

Patient information on herbal supplements is available from an increasing number of sources. The dental health professional is in an ideal posi tion to be a good source for this valuable informa tion, however this is seldom the case. The news media and advertisements supply a vast amount of information about herbal supplements, most of it is to motivate sales, rather than provide helpful information. There are many good sources of unbiased information on this subject. The Complete Guide to Herbal Medicine (Fetrow and Avilia 2000) is an excellent reference guide, mix ing scientific and cultural information about many plant products in a useful and informative fashion. Information is also available online at many web sites dealing with herbal preparations. However, sales are the goal of most of these sites, not patient information. The American Society of Pharmacology and Experimental Therapeutics, a major scientific pharmacology professional society, maintains a plant medicine informational site (http://www.faseb.org/aspet/H\&MIG7.htm\#top) that can act as an entry into this subject for pro fessional and patient.

The University of Washington maintains a very excellent site, "The Medicinal Herb Garden (http://www.nnlm.nlm.nih.gov/pnr/uwmhg/). This is perhaps the best informational Internet site on herbal remedies. Adding tothe value of this site is the direct link to the National Library of Medicine's Pub-Med search engine. This provides immedi ate updating of patient information with current scientific papers on all of the plants listed. Other web sites are also available and can be useful sources of information if the patient is well informed about how to evaluate material found online.

\section{Conclusion}

The widespread use of herbal supplements The herbal supplement question is no longer an exception. makes it essential for healthcare providers to become informed on this topic. Upto-date, scientifically substantiated information tempered with an understanding of the patient's needs is always the best response when a patient asks for a healthcare provider's opinion. 


\section{References}

1. Ernst E. Herbal medications for common ailments in the elderly. Drugs Aging. 1999 Dec;15(6): 423-8.

2. Borchers AT, Keen CL, Stern JS, Gershwin ME. Inflammation and Native American medicine: the roleof botanicals. Am J Clin Nutr. 2000 Aug;72(2):339-47. Review.

3. Melchart D, Walther E, Linde K, Brandmaier R, Lersch C. Echinacea root extracts for the prevention of upper respiratory tract infections: a double-blind,

placebo-controlled randomized trial. Arch Fam Med. 1998 Nov-Dec;7(6):541-5.

4. National Toxicology Program. "Echinacea: treatment or prevention?" Health News 1999;5:7.

5. Cunningham JJ. Micronutrients as nutriceutical interventions in diabetes mellitus. J Am Coll Nutr . 1998 Feb;17(1):7-10. Review.

6. Heiligenstein E, Guenther G. Over-the-counter psychotropics: a review of melatonin, St John's wort, valerian, and kava-kava. J Am Coll Health. 1998 May;46(6):271-6.

7. Fetrow CW, Avila JR. The Complete Guide to Herbal Medicine, Springhouse Corporation, Springhouse, PA, 2000.

8. Smolinske SC. Dietary supplement-drug interactions. J Am Med Womens Assoc. 1999 Fall;54(4):191-2,195. Review.

9. Fugh-Berman A. Herb-drug interactions. Lancet. 2000 Jan 8;355(9198):134-8. Review .

10. O'Hara M, Kiefer D, Farrell K, Kemper K. A review of 12 commonly used medicinal herbs. Arch Fam Med. 1998 Nov-Dec;7(6):523-36. Review.

11. Suzuki O, Katsumata Y, Oya M, Bladt S, Wagner H. Inhibition of monoamine oxidase by hypericin. Planta Med. 1984 Jun;50(3):272-4. No abstract available.

12. Wong AH, Smith M, Boon HS. Herbal remedies in psychiatric practice. Arch Gen Psychiatry. 1998 Nov;55(11):1033-44. Review.

13. Walter G, Rey JM. The relevance of herbal treatments for psychiatric practice. Aust N Z J Psychiatry. 1999 Aug;33(4):482-9; discussion 490-3. Review.

14. Kamuhabwa AR, Roelandts R, de Witte PA. Skin photosensitization with topical hypericin in hairless mice. J Photochem Photobiol B. 1999 Nov-Dec;53(1-3):110-4.

15. Gulick RM, McAuliffe V, Holden-Wiltse J, Crumpacker C, Liebes L, Stein DS, Meehan P, Hussey S, Forcht J, Valentine FT. Phase I studies of hypericin, the active compound in St. John's Wort, as an antiretroviral agent in HIV-infected adults. AIDS Clinical Trials Group Protocols 150 and 258. Ann Intern Med. 1999 Mar 16;130(6):510-4.

16. Hudson JB, Delaey E, de Witte PA. Bromohypericins are potent photoactive antiviral agents. Photochem Photobiol. 1999 Nov;70(5):820-2.

17. Couldwell WT, Gopalakrishna R, Hinton DR, He S, Weiss MH, Law RE, Apuzzo ML, Law RE. Hypericin: a potential antiglioma therapy. Neurosurgery. 1994 Oct;35(4):705-9; discussion 709-10.

18. Hadjur C, Richard MJ, Parat MO, Jardon P, Favier A. Photodynamic effects of hypericin on lipid peroxidation and antioxidant status in melanoma cells. Photochem Photobiol. 1996 Aug;64(2):375-81.

19. VanderWerf QM, Saxton RE, Chang A, Horton D, Paiva MB, Anderson J, Foote C, Soudant J, Mathey A, Castro DJ. Hypericin: a new laser phototargeting agent for human cancer cells. Laryngoscope. 1996 Apr;106(4):479-83.

20. Rose $\mathrm{H}$, Wagner $\mathrm{H}$. The effect of hypericin as a sensitizer of biological systems against visual and ionizing radiation. Radiobiol Radiother 1965;6(4):477-83.

21. Bladt $\mathrm{S}$, Wagner $\mathrm{H}$. Inhibition of MAO by fractions and constituents of hypericum extract. J Geriatr Psychiatry Neurol. 1994 Oct;7 Suppl 1:S57-9.

22. Bennett DA Jr, Phun L, Polk JF, Voglino SA, Zlotnik V, Raffa RB. Neuropharmacology of St. John's Wort (Hypericum). Ann Pharmacother. 1998 Nov;32(11):1201-8.

Review. 
23. Thiede HM, Walper A. Inhibition of MAO and COMT by hypericum extracts and hypericin. J Geriatr Psychiatry Neurol. 1994 Oct;7 Suppl 1:S54-6.

24. Gordon J. SSRI's and St. John's wort: Possible toxicity? Am Fam Phys 1998;57:28-32.

25. Demott K. St. John's wort tied to serotonin syndrome. Clin Psychiatry News 1998;26:28-29.

26. Lantz MS, Buchalter E, Giambanco V. St. John's wort and antidepressant drug interactions in the elderly. J Geriatr Psychiatry Neurol. 1999 Spring;12(1):7-10.

27. Sternbach H. The serotonin syndrome. Am J Psychiatry. 1991 Jun;148(6):705-13. Review .

28. Boudikova-Girard B, Scott MC, Weinshilboum R. Histamine N-methyltransferase: inhibition by monoamine oxidase inhibitors. Agents Actions. 1993 Sep;40(1-2):1-10.

29. Feighner JP. Mechanism of action of antidepressant medications. J Clin Psychiatry. 1999;60 Suppl 4:4-11; discussion 12-3. Review.

30. Jappe U, Franke I, Reinhold D, Gollnick HP. Sebotropic drug reaction resulting from kava-kava extract therapy: a new entity? J Am Acad Dermatol. 1998 Jan;38(1):104-6. No abstract available.

31. Uebelhack R, Franke L, Schewe HJ. Inhibition of platelet MAO-B by kava pyrone-enriched extract from Piper methysticum Forster (kava-kava). Pharmacopsychiatry. 1998 Sep;31(5):187-92.

32. Muller B, Komorek R. [Treatment with Kava--the root to ocombat stress]. Wien Med Wochenschr . 1999;149(8-10):197-201. Review. German.

33. Baum SS, Hill R, Rommelspacher H. Effect of kava extract and individual kavapyrones on neuro transmitter levels in the nucleus accumbens of rats. Prog Neuropsychopharmacol Biol Psychiatry. 1998 Oct;22(7):1105-20.

34. Scherer J. Kava-kava extract in anxiety disorders: an outpatient observational study. Adv Ther. 1998 Jul-Aug;15(4):261-9.

35. Seitz U, Schule A, Gleitz J. [3H]-monoamine uptake inhibition properties of kava pyrones. Planta Med. 1997 Dec;63(6):548-9.

36. Roby CA, Anderson GD, Kantor E, Dryer DA, Burstein AH. St John's Wort: effect on CYP3A4 activi ty. Clin Pharmacol Ther. 2000 May;67(5):451-7.

37. Obach RS. Inhibition of human cytochrome P450 enzymes by constituents of St. John's Wort, an herbal preparation used in the treatment of depression. J Pharmacol

Exp Ther. 2000 Jul;294(1):88-95.

38. Conney A. Induction of microsomal cytochrome P-450 enzymes: the first Bernard B. Brodie lecture at Pennsylvania State University. Life Sci. $1986 \mathrm{Dec}$ 29;39(26):2493-518. Review. No abstract available.

39. Ruschitzka F, Meier PJ, Turina M, Luscher TF, Noll G. Acute heart transplant rejection due to Saint John's wort. Lancet. 2000 Feb 12;355(9203):548-9.

40. Piscitelli SC, Burstein AH, Chaitt D, Alfaro RM, Falloon J. Indinavir concentrations and St John's wort. Lancet. 2000 Feb 12;355(9203):547-8.

41. Baede-van Dijk PA, van Galen E, Lekkerkerker JF. [Drug interactions of Hypericum perforatum (St. John's wort) are potentially hazardous]. Ned Tijdschr Geneeskd. 2000 Apr 22;144(17):811-2. Review. Dutch.

42. Lan LB, Dalton JT, Schuetz EG. Mdr1 limits CYP3A metabolism in vivo. Mol Pharmacol. 2000 Oct;58(4):863-9.

43. Mayhew BS, Jones DR, Hall SD. An in vitro model for predicting in vivo inhibition of cytochrome P450 3A4 by metabolic intermediate complex formation. Drug Metab Dispos. 2000 Sep;28(9):1031-7.

44. Budzinski JW, Foster BC, Vandenhoek S, Arnason JT. An in vitro evaluation of human cytochrome P450 3A4 inhibition by selected commercial herbal extracts and tinctures. Phytomedicine. 2000 Jul;7(4):273-82.

45. Mashour NH, Lin GI, Frishman WH. Herbal medicine for the treatment of cardiovascular disease: clinical considerations. Arch Intern Med. $1998 \mathrm{Nov}$ 9;158(20):2225-34. Review. 
46. Neil HA, Silagy CA, Lancaster T, Hodgeman J, Vos K, Moore JW, Jones L, Cahill J, Fowler GH. Garlic powder in the treatment of moderate hyperlipidaemia: a

controlled trial and meta-analysis. J R Coll Physicians Lond. 1996 Jul-Aug;30(4):329-34.

47 .Isaacsohn JL, Moser M, Stein EA, Dudley K, Davey JA, Liskov E, Black HR. Garlic powder and plasma lipids and lipoproteins: a multicenter, randomized, placebo-controlled trial. Arch Intern Med. 1998 Jun 8;158(11):1189-94.

48. Silagy CA, Neil HA. A meta-analysis of the effect of garlic on blood pressure. J Hypertens. 1994 Apr;12(4):463-8.

49. Bordia A. Effect of garlic on human platelet aggregation in vitro. Atherosclerosis. 1978 Aug;30(4):355-60.

50. Rahman K, Billington D. Dietary supplementation with aged garlic extract inhibits ADP-induced platelet aggregation in humans. J Nutr. 2000 Nov;130(11):2662-5.

51. Grontved A, Hentzer E. Vertigo-reducing effect of ginger root. A controlled clinical study. ORL J Otorhinolaryngol Relat Spec. 1986;48(5):282-6.

52. Langner E, Greifenberg S, Gruenwald J. Ginger: history and use. Adv Ther. 1998 JanFeb;15(1):25-44. Review.

53. Backon J. Ginger: inhibition of thromboxane synthetase and stimulation of prostacyclin: relevance for medicine and psychiatry. Med Hypotheses. 1986 Jul;20(3):271-8. Review.

54. Backon J. Ginger as an antiemetic: possible side effects due to its thromboxane synthetase activity . Anaesthesia. 1991 Aug;46(8):705-6. No abstract available.

55. Cott J. NCDEU update. Natural product formulations available in europe for psychotropic indica tions. Psychopharmacol Bull. 1995;31(4):745-51. Review .

56. Le Bars PL, Katz MM, Berman N, Itil TM, Freedman AM, Schatzberg AF. A placebo-controlled, double-blind, randomized trial of an extract of Ginkgo biloba for dementia. North American EGb Study Group. JAMA. 1997 Oct 22-29;278(16):1327-32.

57. Chung KF, Dent G, McCusker M, Guinot P, Page CP, Barnes PJ. Effect of a ginkgolide mixture (BN 52063) in antagonising skin and platelet responses to platelet activating factor in man. Lancet. 1987 Jan 31;1(8527):248-51.

58. Rowin J, Lewis SL. Spontaneous bilateral subdural hematomas associated with chronic Ginkgo biloba ingestion. Neurology. 1996 Jun;46(6):1775-6. No abstract available.

59. Liberti LE, Der Marderosian A. Evaluation of commercial ginseng products. J Pharm Sci. 1978 Oct;67(10):1487-9.

60. Herbal Roulette. Consumer Reports 1995;698-705.

61. Sotaniemi EA, Haapakoski E, Rautio A. Ginseng therapy in non-insulin-dependent diabetic patients. Diabetes Care. 1995 Oct;18(10):1373-5.

62. Janetzky K, Morreale AP. Probable interaction between warfarin and ginseng. Am J Health Syst Pharm. 1997 Mar 15;54(6):692-3. No abstract available.

63. Miller LG. Herbal medicinals: selected clinical considerations focusing on known or potential drugherb interactions. Arch Intern Med. 1998 Nov 9;158(20):2200-11.

Review.

64. Cupp MJ. Herbal remedies: adverse effects and drug interactions. Am Fam Phys. 1999 Mar 1;59(5):1239-45. Review.

65. Hopkins MP, Androff L, Benninghoff AS. Ginseng face cream and unexplained vaginal bleeding. Am J Obstet Gynecol. 1988 Nov;159(5):1121-2.

66. Zhu M, Chan KW, Ng LS, Chang Q, Chang S, Li RC. Possible influences of ginseng on the phar macokinetics and pharmacodynamics of warfarin in rats. J Phar Pharmacol. 1999 Feb;51(2):175-80.

67. Wustenberg P, Henneicke-von Zepelin HH, Kohler G, Stammwitz U. Efficacy and mode of action of an immunomodulator herbal preparation containing Echinacea, wild indigo, and white cedar. Adv Ther. 1999 Jan-Feb;16(1):51-70. Review.

68. Sun LZ, Currier NL, Miller SC. The American coneflower: a prophylactic role involving nonspecific immunity. J Altern Complement Med. 1999 Oct;5(5):437-46. 
69. Rehman J, Dillow JM, Carter SM, Chou J, Le B, Maisel AS. Increased production of antigen-specific immunoglobulins $\mathrm{G}$ and $\mathrm{M}$ following in vivo treatment with the medicinal plants Echinacea angustifo lia and Hydrastis canadensis. Immunol Lett. 1999 Jun 1;68(2-3):391-5.

70. See DM, Broumand N, Sahl L, Tilles JG. In vitro effects of echinacea and ginseng on natural killer and antibody-dependent cell cytotoxicity in healthy subjects and chronic fatigue syndrome or acquired immunodeficiency syndrome patients. Immunopharmacology . 1997 Jan;35(3):229-35.

71. Brinkeborn RM, Shah DV, Degenring FH. Echinaforce and other Echinacea fresh plant preparations in the treatment of the common cold. A randomized, placebo controlled, double-blind clinical trial. Phytomedicine. 1999 Mar;6(1):1-6.

72. Melchart D, Linde K, Worku F, Sarkady L, Holzmann M, Jurcic K, Wagner H. Results of five ran domized studies on the immunomodulatory activity of preparations of Echinacea. J Altern Complement Med. 1995 Summer;1(2):145-60.

73. Barrett B, Vohmann M, Calabrese C. Echinacea for upper respiratory infection. J Fam Pract. 1999 Aug;48(8):628-35. Review.

74. Blumenthal M, Gruenwald J, et al., Eds. (1998). German Commision E Monographs: Therapeutic monographs on medicinal plants. Austin, TX, American Botanical Council.

75. Kaatz B. Phenytoin suppositories and echinacea. S D J Med. 1997 Sep;50(9):335. No abstract available.

76. Borbas A, Janossy L, Liptak A. Scope and limitation of the application of the (methoxydimethyl)methyl group in the synthesis of 2'-O-, 6'-O- and 2',6'-di-O-(alpha-L-arabinofuranosyl)-beta-D-galactopyranosyl- (1-->6)-D-galactoses. Carbohydr Res. 1999 May 31;318(1-4):98-109.

77. Wagner $\mathrm{H}$, Breu $\mathrm{W}$, et al. In vitro inhibition of arachidonate metabolism by some alkamides and prenylated phenols. Planta Med 1989;55: 566-567.

78. Muller-Jakic B, Breu W, Probstle A, Redl K, Greger H, Bauer R. In vitro inhibition of cyclooxygenase and 5-lipoxygenase by alkamides from Echinacea and Achillea species. Planta Med. 1994 Feb;60(1):37-40.

79. Vavreckova C, Gawlik I, Muller K. Benzophenanthridine alkaloids of Chelidonium majus; I. Inhibition of 5- and 12-lipoxygenase by a non-redox mechanism. Planta Med. 1996 Oct;62(5):397-401.

80. Belch JJ, Hill A. Evening primrose oil and borage oil in rheumatologic conditions. Am J Clin Nutr . 2000 Jan;71(1 Suppl):352S-6S. Review.

81. Horrobin DF. Essential fatty acid metabolism in diseases of connective tissue with special reference to scleroderma and to Sjogren's syndrome. Med Hypotheses. 1984 Jul;14(3):233-47.

82. Ziboh VA, Miller CC, Cho Y. Metabolism of polyunsaturated fatty acids by skin epidermal enzymes: generation of antiinflammatory and antiproliferative metabolites. Am J Clin Nutr. 2000 Jan;71(1 Suppl):361S-6S. Review .

83. Manthorpe R, Hagen Petersen S, Prause JU. Primary Sjogren's syndrome treated with Efamol/Efavit. A double-blind cross-over investigation. Rheumatol Int. 1984;4(4):165-7.

84. Scimore A. US sees the green in herbal supplements. Chem Market Rep 1998;(254): FR 3-4. 


\section{Michael J. Meredith, Ph.D.}

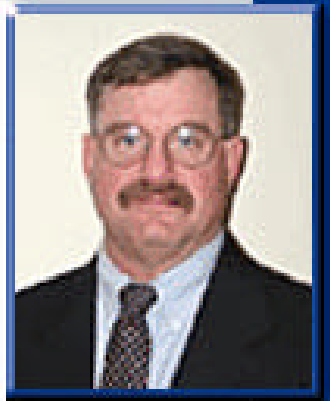

Michael J. Meredith, Ph.D., is an Associate Professor in the Department of Oral Molecular Biology at OHSU. He received BA's in Biology and Chemistry from the University of Kansas and PhD in Biochemistry/Nutrition from Virginia Polytechnic Institute. Dr. Meredith's research is in the area of biochemical toxicology and pharmacology. He has authored more than 75 refereed publications and holds seven US patents dealing with drug delivery systems.

Michael J. Meredith, Ph.D.

Associate Professor of Oral Molecular Biology

Oregon Health Sciences University

611 SW Campus Drive

Portland, OR 97201

503.494 .4463 (V)

503.494 .8619 (fax)

e-mail: mereditm@ohsu.edu

www.oregonomb.org 